\title{
ENTRE SIMULAÇÕES E ALGORITMOS: O DESEMPENHO AMBIENTAL E A PERCEPÇÃO DO USUÁRIO NA ARQUITETURA CONTEMPORÂNEA
}

\section{BETWEEN SIMULATIONS AND ALGORITHMS: ENVIRONMENTAL PERFORMANCE AND USER PERCEPTION IN CONTEMPORARY ARCHITECTURE}

\author{
Letícia de Oliveira Neves ${ }^{1}$ \\ Universidade Estadual de Campinas, \\ Faculdade de Engenharia Civil, Arquitetura \\ e Urbanismo, \\ Campinas - SP \\ Editor Chefe \\ leticia@fec.unicamp.br \\ Regina Coeli Ruschel ${ }^{2}$ \\ Universidade Estadual de Campinas, \\ Faculdade de Engenharia Civil, Arquitetura \\ e Urbanismo, \\ Campinas - SP \\ Editor Chefe \\ parc@fec.unicamp.br \\ Sidney Piochi Bernardini ${ }^{3}$ \\ Universidade Estadual de Campinas, \\ Faculdade de Engenharia Civil, Arquitetura \\ e Urbanismo, \\ Campinas - SP \\ Editor Chefe \\ sidpiochi@fec.unicamp.br \\ Daniel de Carvalho Moreira 4 \\ Universidade Estadual de Campinas, \\ Faculdade de Engenharia Civil, Arquitetura \\ e Urbanismo, \\ Campinas - SP \\ Editor Chefe \\ damore@fec.unicamp.br
}

\section{Editorial}

O segundo número do Volume 9 de 2018 da PARC Pesquisa em Arquitetura e Construção é composto por artigos de pesquisa e de revisões sistemáticas da literatura desenvolvidos por pesquisadores dos estados brasileiros de Alagoas, Distrito Federal, Minas Gerais, Pernambuco, Rio de Janeiro e São Paulo. As instituições de ensino e pesquisa envolvidas nos estudos apresentados são: Centro Superior de Juiz de Fora, Universidade de Pernambuco, Universidade Estadual de Campinas, Universidade Federal de Alagoas, Universidade Federal de Brasília, Universidade Federal de Juiz de Fora, Universidade Federal de Viçosa e Universidade Federal do Rio de Janeiro. Neste número houve uma inversão, comparada a números anteriormente publicados, isto é, as áreas de formação dos autores concentram-se em Engenharia Civil, na maioria, e depois em Arquitetura. As temáticas abordadas nos artigos de pesquisa têm enfoque na ventilação natural e a qualidade ambiental das cidades, desempenho de vedações verticais e simulações termo energéticas. As revisões sistemáticas da literatura abordam pesquisas em sistemas generativos em projeto e sobre a percepção do valor na habitação. Assim, inspiram o título deste editorial.

O primeiro artigo deste volume da PARC - dos autores Aline Maria Pereira Nogueira, Iuri Ávila Lins de Araújo, Leonardo Salazar Bittencourt e Gabriella Restaino, da Universidade Federal de Alagoas - investiga os efeitos do adensamento por verticalização no microclima urbano, avaliando potenciais impactos de decisões de planejamento urbano na qualidade ambiental das cidades. Foi desenvolvido um experimento simulado de uma fração do bairro Guaxuma, o loteamento Gurgury, situado no litoral norte da cidade de Maceió AL. Realizaram-se análises comparativas computacionais simulando temperatura e velocidade do ar, em três diferentes cenários de verticalização. Os resultados demonstraram que a verticalização afetou o microclima local, principalmente o desempenho da ventilação natural, demonstrando, surpreendentemente, que edificações mais altas, com menores taxas de ocupação e com maior afastamento entre edifícios são preferíveis, favorecendo uma maior circulação do ar.

\section{How to cite this article:}

NEVES, Letícia de Oliveira et al. Entre simulações e algoritmos: o desempenho ambiental e a percepção do usuário na arquitetura contemporânea. PARC Pesquisa em Arquitetura e Construção, Campinas, SP, v. 9, n. 2, p. 69-71, jun. 2018. ISSN 1980-6809. Disponível em: <https://periodicos.sbu.unicamp.br/ojs/index.php/parc/article/view/8652787>. Acesso em: 28 jun. 2018. doi:https://doi.org/10.20396/parc.v9i2.8652787... 
Matheus Menezes Oliveira e Joyce Correna Carlo, da Universidade Federal de Viçosa, analisam três métodos de simulação de fluxo de ar de chaminés solares no software EnergyPlus, de forma a compará-los e qualificá-los. Os autores levantam as vantagens e desvantagens do uso de cada método, por meio da comparação com um modelo previamente calibrado, advindo de um estudo anterior. Os resultados apontam o modelo de cálculo ThermalChimney como o mais adequado para simular os efeitos da ventilação natural em chaminés solares. Os resultados desta pesquisa contribuem para preencher uma lacuna de conhecimento sobre o tema, ao propor o uso de indicadores para comparação entre diferentes modelos de cálculo utilizados em simulações termo energéticas.

O artigo dos autores Fábia Kamilly Gomes de Andrade, Alberto Casado Lordsleem Jr., Pedro Henrique Rosa Souza e José Victor Pereira dos Santos Veríssimo, da Universidade de Pernambuco, avaliam a conformidade de vedações verticais aos critérios de desempenho acústico estabelecidos pela norma de desempenho, ABNT NBR 15575-2013. Estudos de campo foram realizados em 15 edifícios multipavimentos, visando analisar o tipo de componente e as espessuras total e do revestimento de paredes internas e externas. Os resultados mostram que apenas $25 \%$ das vedações internas e $10 \%$ das vedações externas da amostra estão em conformidade com a norma. Constatou-se também que as vedações em bloco de concreto apresentaram resultados superiores às de bloco cerâmico, tijolo e gesso, para os dois casos.

Lucas Rosse Caldas, da Universidade Federal do Rio de Janeiro, e Michele Tereza Marques Carvalho, da Universidade de Brasília, também avaliam o desempenho de vedações verticais de edificações habitacionais, mas com um enfoque mais amplo, abrangendo o desempenho acústico, térmico e ambiental de diferentes sistemas construtivos. A avaliação foi realizada por meio de um estudo de caso, realizado com base em pesquisa bibliográfica e documental. O Processo de Análise Hierárquica (Analytic Hierarchy Process - AHP) foi utilizado para agregar os critérios avaliados a um único indicador de desempenho global (IDG), de forma a auxiliar na tomada de decisão do projetista. Pela análise realizada, verificou-se que a alvenaria de blocos de concreto é o sistema construtivo mais vantajoso, na maioria dos cenários avaliados.
O artigo de Vanda Alice Garcia Zanoni, José Manoel Morales Sánchez e Elton Bauer, da Universidade de Brasília, apresenta um estudo comparativo de métodos de quantificação de chuva dirigida nas fachadas de edificações. Por meio de uma revisão da literatura, foram selecionados três métodos semi-empíricos para quantificação de chuva dirigida: ISO 15927-3:2009, ASHRAE 160:2009, e o método do programa higrotérmico computacional WUFI Pro 5.3. Os métodos foram aplicados em estudos descritivos e analíticos, realizados no contexto urbano da cidade de Brasília-DF. Tendo em vista que os métodos analisados adotam diferentes parâmetros para definição dos coeficientes que retratam as condições de exposição do edifício e sua inserção no contexto urbano, constatou-se que a escolha do método implica na obtenção de diferentes resultados, sendo observada uma variação de até $65 \%$.

Este número finaliza com duas Revisões Sistemáticas da Literatura (RSL). A primeira RSL é de Leonardo Sanches - do Centro de Ensino Superior de Juiz de Fora - José Gustavo Francis Abdalla e Klaus Chaves Alberto - da Universidade Federal de Juiz de Fora - que traçam o panorama atual de pesquisas relacionadas aos Sistemas Generativos de Projeto. O protocolo de revisão envolveu buscas de artigos publicados nos periódicos e anais de eventos incluídos no Portal de Periódicos CAPES e no Índice Acumulativo CumInCAD. Os termos de busca foram: arquitetura, sistemas generativos e projeto algorítmico. O período abrangido resgata os primórdios da temática até à atualidade. São identificados todos os estudos ao longo do tempo, principais temáticas abordadas, métodos utilizados, as obras mais referenciadas e os principais autores na temática. Esta revisão sistemática é completa e se promove um ponto de partida para pesquisadores iniciantes.

A RSL dos autores Karen Fontanella Setei, Patricia Stella Pucharelli Fontanini, Ariovaldo Denis Granja, Marina Sangoi de Oliveira Ilha e Flávio Augusto Picchi - todos da Universidade Estadual de Campinas - aborda a percepção de valor de usuários de edifícios habitacionais identificando estudos nas temáticas de: avaliação de satisfação, avaliação de percepção de valor e definição de requisitos de projeto a partir dos requisitos dos usuários. $\mathrm{O}$ protocolo de revisão envolveu buscas de artigos publicados entre 2007 e 2017 nas bases de dados ProQuest, Scielo, Science Direct, Scopus e Web of Science. Os estudos obtidos evidenciaram o caráter 
diversificado das pesquisas relacionadas à percepção dos usuários, devido à variedade de situações, métodos e particularidades considerados em cada pesquisa. Reforçase a importância da etapa de retroalimentação do processo de projeto de habitações, para que os requisitos dos usuários sejam efetivamente compreendidos e incorporados aos empreendimentos habitacionais.

Desejamos a todos uma boa leitura.

\section{Agradecimentos}

Agradecemos aos avaliadores pelo tempo despendido e valiosas considerações tecidas sobre os artigos submetidos.

\section{${ }^{1}$ Letícia de Oliveira Neves}

Arquiteta Urbanista. Doutora em Arquitetura, Tecnologia e Cidade pela Universidade Estadual de Campinas. Professora Doutora na Faculdade de Engenharia Civil, Arquitetura e Urbanismo da UNICAMP. Endereço postal: Av. Albert Einstein, 951, Campinas, SP, Brasil, CEP 13.083-852.

\section{${ }^{2}$ Regina Coeli Ruschel}

Engenheira Civil. Doutor em Engenharia Elétrica e da Computação (UNICAMP). Livre Docente em Projeto Auxiliado por Computador (UNICAMP). Professora e Pesquisadora Colaboradora (FEC-UNICAMP) Endereço postal: Av. Albert Einstein, 951, Campinas, SP, Brasil, CEP 13.083-852.

\section{${ }^{3}$ Sidney Piochi Bernardini}

Arquiteto Urbanista. Doutor em Arquitetura e Urbanismo (FAU-USP). Professor Doutor na Faculdade de Engenharia Civil, Arquitetura e Urbanismo da UNICAMP. Endereço postal: Av. Albert Einstein, 951, Campinas, SP, Brasil, CEP 13.083-852.

\section{${ }^{4}$ Daniel de Carvalho Moreira}

Arquiteto Urbanista. Doutor em Engenharia Civil (UNICAMP). Professor Doutor II na Faculdade de Engenharia Civil, Arquitetura e Urbanismo da UNICAMP. Endereço postal: Av. Albert Einstein, 951, Campinas, SP, Brasil, CEP 13.083-852. 